\title{
O QUE DIZEM AS MATRIZES DE HABILIDADES SOBRE A LEITURA EM AMBIENTES DIGITAIS
}

\author{
Ana Elisa Ribeiro* \\ Carla Viana Coscarelli**
}

RESUMO: Com base em análises da matriz de Língua Portuguesa do Saeb, utilizada em avaliações de larga escala no Brasil, este trabalho discute a vinculação dessa matriz às práticas de leitura e à cultura escrita impressa, além de propor uma reflexão sobre a complexidade dos descritores que compõem a matriz em relação às práticas de leitura reais. Propõe-se a diferenciação entre matriz de avaliação e matriz de ensino, assim como se considera de suma importância que o ato de ler seja abordado em seus aspectos multimodais e relativos ao letramento digital.

Palavras-chave: Matriz; Habilidades de Leitura; SAEB; ENEM; Letramento Digital.

\section{WHAT ABILITY MATRICES CONVEY ABOUT READING IN DIGITAL ENVIRONMENTS}

ABSTRACT: Based on an analysis of the Saeb's Matrix on Portuguese Language, widely used in evaluations in Brazil, we discuss in this paper the relationship of this matrix to reading practices and printed writing culture. We also propose a discussion about the complexity of abilities that compose the matrix, as far as real reading practices are concerned. We propose the necessity to make a clear distinction between a matrix for evaluation purposes and a matrix designed for teaching purposes. It is also very important to consider aspects related to the multimodal and digital literacy as a crucial part of the act of reading.

Keywords: Matrix; Reading Abilities; SAEB; ENEM; Digital Literacy.

\footnotetext{
* Doutora em Linguística Aplicada pela Universidade Federal de Minas Gerais (UFMG); Professora do Programa de Pós-graduação em Estudos de Linguagens do Centro Federal de Educação Tecnológica de Minas Gerais (CEFET-MG). E-mail: anadigital@gmail.com * * Doutora em Estudos Linguísticos pela Universidade Federal de Minas Gerais (UFMG) e Professora adjunta da Universidade Federal de Minas Gerais (UFMG).E-mail: cvcosc@yahoo.com.br
} 


\section{De onde vem a matriz?}

Enem, Enade e Provão são apenas alguns exemplos de testes que ficaram conhecidos dos estudantes e dos professores brasileiros. $\mathrm{O}$ Enem (Exame Nacional do Ensino Médio) é uma "prova” impressa, com questões de múltipla escolha e abertas, construída para avaliar habilidades de estudantes que se formam no ensino médio; o Enade (Exame Nacional de Desempenho de Estudantes) faz algo semelhante com estudantes de graduação "em relação aos conteúdos programáticos, suas habilidades e competências” (BRASIL, 2010); e Provão foi o apelido que o Enade ganhou quando surgiu, em 1996.

A composição dessas "provas" começa muito antes da redação de suas questões. Para que se formulem itens (como são chamadas as questões dos testes), é necessário que o formulador se baseie em matrizes de habilidades, que são constituídas por equipes de especialistas, depois de muita discussão e várias reuniões.

As matrizes contêm uma coleção de habilidades (Descritores), separadas por categorias (Tópicos), que se espera ou se deseja que os estudantes de determinado nível de ensino tenham desenvolvido ao longo de seus anos de escolaridade. A matriz é constituída por descritores, ou seja, descrições objetivas de qual é a habilidade a ser focalizada, em geral escritas com um verbo no infinitivo, por exemplo: "inferir", "localizar", "identificar", "distinguir", etc.

Neste trabalho, discutiremos aspectos da matriz de Língua Portuguesa utilizada como base para a composição das provas do ensino básico. Nossa intenção, com base em trabalhos científicos que a empregaram para estudar aspectos da leitura em ambiente digital, especialmente por meio de computadores ligados à web, é refletir sobre como essa matriz é [i] impregnada de valores ligados à cultura escrita impressa; [ii] forjada com base em pressupostos que não levam em consideração a multimodalidade dos textos que circulam na sociedade; [iii] redigida de maneira imprecisa em grande parte dos descritores; e [iv] carente de uma ampliação para que agregue elementos importantes para uma avaliação menos vaga de habilidades sustentadas por experiências de leitura em ambiente digital. Com isso, mencionaremos algumas propostas de matrizes voltadas também para as habilidades da leitura em ambientes digitais.

Nosso intuito não é desmerecer as matrizes, uma vez que elas, até o momento, servem bem aos propósitos para os quais foram feitas. 
Queremos, no entanto, chamar a atenção para o fato de que essas matrizes ainda não contemplam habilidades requeridas nos ambientes digitais, além de não serem matrizes de ensino. São matrizes que têm como propósito avaliar o desempenho dos alunos em algumas habilidades consideradas relevantes, mas não podem ter tomadas como matrizes de ensino, que devem ser mais detalhadas e mais completas que as matrizes gerais de avaliação. O principal ponto que desejamos considerar aqui é: já não será hora de incluir na matriz do Saeb (ou em outras) habilidades de leitura em ambientes digitais? Esse questionamento parte de um pressuposto: o de que há habilidades que são exclusivas do ambiente digital.

\section{Pesquisas em leitura na web}

Desde a relativa popularização da World Wide Web, muitos pesquisadores têm se sentido provocados por questões relacionadas às práticas de leitura (e escrita) mediadas pelo computador ou, se não mediadas, suportadas pela máquina. Para alguns, práticas exclusivas e inéditas surgiram com o advento do computador ligado à internet; para outros, essas práticas são “adaptações", "remidiações" (BOLTER; GRUSIN, 2000), "transmutações" ou reconfigurações de práticas preexistentes. Há ainda quem arrisque afirmar que não houve mudanças consideráveis surgidas com base na experiência de ler em computador ou em outra tela da mesma família.

Nos Estudos Linguísticos, diversos trabalhos foram feitos na tentativa de responder a questões tais como "ler na tela é diferente de ler no papel?”. Com diversas formulações, essa questão permeou muitas pesquisas e ora trouxe resultados mais próximos da crença, ora tendentes à intensificação das perguntas, ora alinhados a métodos empíricos de observação do leitor.

Diversos desses estudos basearam-se em matrizes de habilidades para construir métodos de pesquisa e para fundamentar a composição de testes e questionários padronizados. É o caso dos trabalhos de Coscarelli (2005a e b), Araújo (2006), Ribeiro (2003; 2008), Novais (2008), Duarte (2008) e Paiva (2009).

Em Ribeiro (2008), uma das questões que se colocava, em relação a práticas com o computador, era: “quais habilidades é necessário desenvolver para que seja possível ler melhor (com tudo o que implica 
saber ler, para muito além da decodificação do texto)?”. Com base na matriz de Língua Portuguesa do Saeb, a pesquisadora compôs testes de leitura que focalizavam habilidades consideradas importantes para uma boa interação com jornais. De acordo com os resultados dessa investigação, navegar e ler são etapas diferenciadas da leitura, concorrendo ambas para a composição de uma competência, que, se relacionada a práticas de leitura (e escrita) em ambiente suportado por computador ou, mais abrangentemente, por tecnologia digital, configura o que se convencionou chamar de "letramento digital", embora não se tenha tanta clareza do que é, de fato, ser um letrado digital.

É justamente essa falta de clareza que provoca muitos estudiosos do tema a tentarem definir o letramento digital ou a proporem matrizes desse letramento, com descritores pensados com base nas práticas possíveis diante de ambientes digitais, sejam eles máquinas de busca, sites de lojas, bibliotecas virtuais ou jogos eletrônicos.

\section{A matriz de leitura do Saeb}

O Saeb é composto de duas avaliações: a Avaliação Nacional da Educação Básica (Aneb) e a Avaliação Nacional do Rendimento Escolar (Anresc). A primeira focaliza a gestão dos sistemas educacionais e é, na verdade, o que se conhece como Saeb; a segunda é mais detalhada e extensa e tem foco nas unidades escolares. Essas avaliações

produzem informações a respeito da realidade educacional brasileira e, especificamente, por regiões, redes de ensino pública e privada nos estados e no Distrito Federal, por meio de exame bienal de proficiência, em Matemática e em Língua Portuguesa (leitura), aplicado em amostra de alunos de $4^{\mathrm{a}}$ e $8^{\mathrm{a}}$ séries do ensino fundamental e da $3^{a}$ série do ensino médio. (BRASIL, 2007)

O Saeb é desenvolvido pelo Instituto Nacional de Estudos e Pesquisas Educacionais Anísio Teixeira (Inep), autarquia do Ministério da Educação (MEC), e os levantamentos feitos a partir desse instrumento "permitem acompanhar a evolução da qualidade da Educação ao longo dos anos” (BRASIL, 2007).

A Matriz de Referência de Língua Portuguesa tem como foco "voltar-se para a função social da língua" e privilegia as habilidades de lei- 
tura. Para isso, busca aferir o conhecimento dos leitores em "diferentes níveis de compreensão, análise e interpretação". Os descritores relacionados nessa matriz "têm como referência algumas das competências discursivas dos sujeitos, tidas como essenciais na situação de leitura” (BRASIL, 2007).

Segundo explicitado nos documentos oficiais que tratam da matriz, são abordados: procedimentos de leitura; implicações do suporte, do gênero e/ou do enunciador na compreensão do texto; relação entre textos; coerência e coesão no processamento do texto; relações entre recursos expressivos e efeitos de sentido; e variação linguística. Ribeiro (2008) focalizou procedimentos, implicações do suporte e recursos expressivos que produzem efeitos de sentido. Paiva (2009) destacou, em sua pesquisa sobre infográficos, aspectos da multimodalidade. Duarte (2008) focalizou relações entre suporte e texto, além de aspectos da relação imagem/palavra.

É possível, como se pode ver, selecionar aspectos da matriz, conforme o foco da pesquisa e o interesse de investigação do pesquisador. Para uma melhor visualização disso, é importante conhecer a matriz de Língua Portuguesa do Saeb para o final do ensino fundamental (oitava série) e para o final do ensino médio (terceiro ano).

QUADRO 1: Matriz de LP do ensino fundamental ( $8^{\mathrm{a}}$ série) e médio ( $3^{\circ}$ ano).

Tópico I. Procedimentos de Leitura

D1 - Localizar informações explícitas em um texto.

D3 - Inferir o sentido de uma palavra ou expressão.

D4 - Inferir uma informação implícita em um texto.

D6 - Identificar o tema de um texto.

D11 - Distinguir um fato da opinião relativa a esse fato.

Tópico II. Implicações do Suporte, do Gênero e lou do Enunciador na Compreensão do Texto

D5 - Interpretar texto com auxílio de material gráfico diverso (propagandas, quadrinhos, foto, etc.).

D12 - Identificar a finalidade de textos de diferentes gêneros.

\section{Tópico III. Relação entre Textos}

D20 - Reconhecer diferentes formas de tratar uma informação na comparação de textos que tratam do mesmo tema, em função das condições em que ele foi produzido e daquelas em que será recebido.

D21 - Reconhecer posições distintas entre duas ou mais opiniões relativas ao mesmo fato ou ao mesmo tema.

Tópico IV. Coerência e Coesão no Processamento do Texto

D2 - Estabelecer relações entre partes de um texto, identificando repetições ou substituições 
que contribuem para a continuidade de um texto.

D7 - Identificar a tese de um texto.

D8 - Estabelecer relação entre a tese e os argumentos oferecidos para sustentá-la.

D9 - Diferenciar as partes principais das secundárias em um texto.

D10 - Identificar o conflito gerador do enredo e os elementos que constroem a narrativa.

D11 - Estabelecer relação causa/consequêência entre partes e elementos do texto.

D15 - Estabelecer relações lógico-discursivas presentes no texto, marcadas por conjunções, advérbios, etc.

\section{Tópico V. Relações entre Recursos Expressivos e Efeitos de Sentido}

D16 - Identificar efeitos de ironia ou humor em textos variados.

D17 - Reconhecer 0 efeito de sentido decorrente do uso da pontuação e de outras notações.

D18 - Reconhecer 0 efeito de sentido decorrente da escolha de uma determinada palavra ou expressão.

D19 - Reconhecer o efeito de sentido decorrente da exploração de recursos ortográficos e/ou morfossintáticos.

\section{Tópico VI. Variação Lingüística}

D13 - Identificar as marcas lingüísticas que evidenciam o locutor e o interlocutor de um texto.

FONTE: INEP. http://www.inep.gov.br/basica/saeb/matrizes/topicos_descritores_port.htm

Como se pode notar, os tópicos abordados pela matriz, tanto no final do ensino fundamental quanto no final do ensino médio, são os mesmos: Procedimentos de leitura; Implicações do suporte, do gênero e/ou do enunciador na compreensão do texto; Coerência e coesão no processamento do texto; Relações entre recursos expressivos e efeitos de sentido; e Variação linguística. Em cada um desses tópicos, diversas habilidades seriam desejáveis ao leitor escolarizado.

Ainda que essa organização seja importante para orientar a construção dos testes e os torne menos vulneráveis com relação à avaliação, é importante questionar se apenas 21 descritores são suficientes para dar conta da complexidade das operações de leitura. Também é interessante enfatizar que uma série desses descritores costuma funcionar (em termos de processamento de leitura, expressão de extração psicolinguística e até computacional) de maneira simultânea ou muito relacionada. Por outro lado, uma quantidade muito grande de descritores poderia inviabilizar a construção de instrumentos de avaliação. A configuração atual da matriz enfoca elementos do processamento leitor e pouco ou nada dedica aos modos de circulação dos textos, aos seus suportes ou à sua relação com ambientes de leitura, muito menos os digitais.

Conforme mostra o quadro (FIG. 1), os cinco descritores do Tópico I (Procedimentos de leitura) são idênticos para o ensino funda- 
mental e para o médio, o que quer dizer que, em relação aos procedimentos, na oitava série já é esperado que o estudante opere com intimidade a localização de informações, a inferência de informações implícitas e explícitas, a identificação de temas (aspecto global do texto) e a distinção entre o que seja fato e o que seja opinião.

No Tópico II, os descritores também são os mesmos para ambos os níveis de formação. Pela matriz, as implicações do suporte, do gênero e/ou do enunciador para a leitura não apenas podem ocupar o mesmo espaço no quadro como se especificam em apenas dois descritores: interpretar textos com o auxílio de material gráfico e identificar a finalidade dos textos.

No Tópico III, Relação entre textos, dois descritores dão conta das habilidades de reconhecer formas diversas de tratar informações, considerando-se textos que tratem do mesmo tema. Além disso, o reconhecimento de posicionamentos diferentes sobre um assunto é abordado.

O Tópico IV apresenta sete descritores, todos relacionados a coesão e coerência, aspectos considerados fundamentais à textualidade (HALLIDAY; HASAN, 1976; BEAUGRANDE; DRESSLER, 1981; COSTA VAL, 1991; 2001). Não por acaso, este é o mais extenso tópico da matriz, à qual subjaz um foco maior sobre o texto verbal em suas relações internas. Ser habilidoso com coesão e coerência quer dizer, segundo a matriz, relacionar partes do texto e sua continuidade, identificar a tese que o texto defende, relacionar essa tese aos argumentos que a sustentam, distinguir partes principais e secundárias do texto, identificar o conflito estabelecido no enredo e outros elementos da narrativa, estabelecer relações de causa e consequência e relações lógico-discursivas marcadas por palavras e expressões.

No Tópico V, a matriz elenca quatro habilidades: Identificar ironia e humor, reconhecer efeitos de sentido ensejados por pontuação e outras notações, identificar efeitos de palavras e expressões específicas e o efeito de sentido decorrente de escolhas ortográficas ou morfossintáticas.

No último Tópico, a Variação Linguística é abordada por meio da habilidade de identificar marcas linguísticas que evidenciem locutor e interlocutor.

Se os Tópicos e os descritores são os mesmos, em que momento a matriz de LP do ensino médio se diferencia da do ensino fundamen- 
tal? A essa questão subjaz a ideia de que deve haver uma progressãoo e uma complexificação das habilidades. Um estudante do final do ensino médio deve tser capaz de ler textos mais complexos do que um estudante do EF. Deve ter desenvolvido habilidades de leitura mais aprofundadas e abrangentes do que um estudante que termina a oitava (ou nona) série,er capaz de ler lendo proficientemente textos mais longos, que tratam de assuntos pouco familiares, que apresentem relações intertextuais e que explorem recursos linguísticos como vocabulário e estruturação sintática mais complexos. Nos documentos oficiais que explicam a matriz do Saeb, essa diferenciação aparece nas explicitações sobre cada tópico, na fundamentação de cada elemento da matriz e, principalmente, nos exemplos dados.

Deve-se notar que, embora a matriz apresentada possa ser usada para avaliar a leitura de textos tanto impressos quanto digitais, ela foi feita para avaliar textos impressos. Essa matriz não leva em consideração elementos típicos dos ambientes digitais, como a hipertextualiade digital, elementos da interface - ícones, menus, barras, abas, entre outros -, a busca e a seleção de informações em ambientes digitais, a multimodalidade mais complexa e evidente, em muitos casos. Além disso, não considera também aspectos relativos ao design (paratextos) dos textos em diversos ambientes, incluindo o impresso ou a navegação necessária em interfaces complexas. Na matriz do Saeb, o trabalho com multimodalidade e design dos textos só é explicitamente marcado em D5 - Interpretar texto com auxílio de material gráfico diverso (propagandas, quadrinhos, foto, etc.). Esse descritor, além de muito amplo, não menciona aspectos gráficos como boxes, colunas, ícones, entre outros elementos comuns em textos tanto impressos quanto digitais, que, em geral, não existem apenas para "auxiliar" o texto verbal.

Ribeiro (2008) fez uma investigação em que estudantes do início do ensino superior (egressos do ensino médio) respondiam a testes propostos com base na matriz de LP do Saeb. Como o objeto de estudo era a leitura de jornais impressos e digitais, a pesquisadora focalizou os descritores D1, D2, D11, D17, ou seja, um descritor de procedimentos de leitura, dois relacionados a coesão e coerência e um ligado às relações entre recursos expressivos e efeitos de sentido. A autora comenta que um descritor como D5 (Interpretar texto com o auxílio de material gráfico diverso - propagandas, quadrinhos, foto, etc.) é de suma importância na leitu- 
ra de jornais, mas não aborda esse aspecto, atendo-se a elementos verbais. Novais (2008), Duarte (2008) e Paiva (2009), por tratarem primordialmente de aspectos relacionados à visualidade, enfatizariam a importância do Descritor 5.

Ribeiro (2008), por sua vez, afirma que o Saeb não cobre todas as habilidades de leitura que ela considera importantes, especialmente aquelas ligadas ao projeto gráfico dos jornais. No entanto, é possível dizer que um descritor como D5 abarque tal aspecto de um objeto de leitura. A observação que se pode fazer quanto a isso é que uma matriz de habilidades como esta poderia evitar vagueza em suas definições, por exemplo, eliminando o uso de etc. ou de expressões como "diverso", "variados" ou "outras". Uma defesa de D5 na matriz de LP do Saeb alegaria que "material gráfico diverso" acolhe quantos elementos não-verbais se possa pensar. Além disso, o descritor enumera fotos, quadrinhos e propagandas como "material gráfico", deixando o "etc." por conta do leitor. O layout, como uma modalidade importante (KRESS; VAN LEEUWEN, 2006) e com impacto sobre a compreensão (RIBEIRO, 2009) (o layout podendo ser entendido como a disposição espacial de elementos na página como texto, fios, cores, fontes, corpos de fontes, agrupamentos e propostas de navegação), poderia estar incluído em D5. De outro lado, sabe-se que, em geral, as interfaces entre os estudos linguísticos e o design ainda não costumam ser iluminadas nas pesquisas tanto de linguistas quanto de designers (RIBEIRO, 2009), embora sejam fundamentais para a compreensão de textos.

Segundo Ribeiro (2008), “ainda que a matriz tente 'cercar' habilidades de leitura importantes, apenas com as que estão elencadas, um leitor não se torna, de fato, competente para ler". Embora seja possível isolar esses descritores para fins de avaliação, em situações cotidianas de leitura, esses descritores não "funcionam sozinhos". A autora exemplifica que, quando solicitado a resumir uma notícia, "o leitor acaba relacionando D5, D6, D7, D8 e D9, respectivamente as habilidades de interpretar textos com o auxílio de material gráfico (fotos, quadrinhos, etc.), perceber o tema e a tese de um texto, além de relacioná-la aos argumentos que a sustentam ou a diferenciar partes secundárias de partes principais".

Ainda que a matriz não dê conta de cercar todos os aspectos da leitura, ela tem o mérito de lançar um olhar sobre o ato de ler que explicita que ele seja muito mais do que apenas decodificação. O professor que 
toma conhecimento de matrizes como esta pode "acordar" para o fato de que ler exige mais do que uma relação estreita com palavras e códigos.

Em sua pesquisa, Ribeiro (2008) propõe aos leitores recontar, de forma resumida, as notícias lidas no papel e na tela. Essa sumarização é uma forma de verificar a compreensão de textos exaustivamente empregada como método de coleta de dados em trabalhos de psicolinguística, além de ser uma das técnicas offline mais conhecidas de se pesquisar leitura, relatada em diversos trabalhos de ampla circulação (BRANSFORD; JOHNSON, 1973; ANDERSON; PICHERT, 1978; KINTSCH; VAN DIJK, 1978; THORNDYKE, 1977).

Coscarelli (1999) considera que:

Para resumir um texto, é preciso primeiramente entendê-lo (o que já inclui diversas operações inferenciais que vão desde a ligação de elementos anafóricos a seus antecedentes até a depreensão das macroproposições do texto, que é a identificação das informações mais importantes dele para os objetivos do leitor), depois construir a estrutura macroproposicional do texto, definindo, para isso, a organização hierárquica dessas macroproposições. E, quanto melhor se conhece o assunto, quanto mais claro e organizado for o texto, e quanto mais tempo houver, mais fácil será a tarefa de fazer um resumo. Tudo isso, sem falar na intimidade do leitor com a produção dessa tarefa e com o tipo de texto que está sendo resumido (COSCARELLI, 1999, p. 113).

Pedir ao leitor para recontar o texto é, certamente, uma forma de verificar, por exemplo, se ele chegou a alguma conclusão sobre o tema de um texto (D6), se identificou sua tese (D7) ou mesmo se distinguiu suas partes principais de secundárias (D9). Em sua maioria, essas são habilidades de identificação de coesão e coerência ou procedimentos de leitura.

A relação entre os descritores no processamento real de um texto pode ser também comentada em relação, por exemplo, a D17 (Reconhecer o efeito de sentido decorrente do uso de pontuação e de outras notações"). Ribeiro (2008) escolheu o emprego de aspas, notação de múltiplos usos, considerada importante na leitura de notícias. A aparente simplicidade dessa habilidade trouxe à tona, mais uma vez, a necessidade de que o leitor seja capaz de distinguir fatos de opiniões (D11 4) e de reconhecer posicionamentos distintos entre duas ou mais opiniões (D21), por exemplo. No uso de aspas podem estar marcadas as vozes, a ironia, o empréstimo linguístico (incluído em D13, D16), a brincadeira, a mistura de registros (D13, mais uma vez), assim como, nessas vozes, os 
posicionamentos e, dentro deles, o que é fato, o que é opinião e mesmo a distinção entre narrador e personagem. Mais do que isso, o uso de aspas deve explicitar a edição do texto, feita pelo editor ou pelo jornalista, autorizado a recortar, copiar e remontar os discursos de todos em um tecido aparentemente inteiriço. Tudo isso, complexo como está descrito, pode subjazer ao uso das aspas. No entanto, como mostra Ribeiro (2008), leitores do início do ensino superior podem não ser capazes sequer de ir além do reconhecimento de aspas como uma "norma da ABNT".

Há muita complexidade envolvida em cada descritor. $\mathrm{O}$ fato de ser uma matriz geral de avaliação da leitura pode ser uma justificativa para que cada item que a compõe seja propositadamente vago e amplo, pois assim se acolhe uma diversidade de possibilidades e níveis de dificuldade da mesma habilidade. No entanto, se pensarmos na formação dos alunos, devemos fatorar esses descritores, tendo consciência da complexidade de cada um deles, ou seja, o professor deve saber que cada um desses descritores engloba uma gama enorme de possibilidades, a exemplo do que mostramos com o uso de aspas.

O descritor D17 - Reconhecer o efeito de sentido decorrente do uso de pontuação e de outras notações - não envolve apenas o uso de aspas, mas de sinais de pontuação e outras notações, incluindo, portanto, vírgula, exclamação, reticências, negritos, itálicos, uso de maiúsculas, entre outros. Cada um desses sinais de pontuação pode representar diversos sentidos diferentes, dependendo do gênero e da situação em que foram usados. O uso de maiúsculas, por exemplo, em um jornal, costuma sinalizar as manchetes e, assim, indicar a relevância daquele texto ou a atenção que deve ser dada a ele. Já em um e-mail ou em histórias em quadrinhos, costuma indicar que a pessoa ou personagem está gritando. Além desses, há muitos outros usos de maiúsculas. $\mathrm{E}$ isso acontece com cada um dos sinais de pontuação e com cada uma das diferentes notações que o autor escolher para usar em seu texto, cabendo ao leitor identificar o efeito de sentido pretendido por esse uso, que algumas vezes é de fácil identificação e outras, é mais sutil.

Comentários semelhantes também podem ser feitos em relação a D4 (Inferir uma informação implícita em um texto.) e D15 (Estabelecer relações lógico-discursivas presentes no texto, marcadas por conjunções, advérbios, etc.). Inferir não é uma única operação cognitiva. Há inúmeros tipos de inferências (conectivas, elaborativas, de motivo, de instrumento, de 
causa e consequência, entre outras que podem ser encontradas em estudos como os feitos por Garnham (1989), Carpenter e Just (1977), Seifert (1990), van den Broek, (1990a e 1990b), Clark (1977), Keenan et al. (1990), Scott (1985), só para sitar alguns autores. Cada um desses tipos requer habilidades e conhecimento diferentes. No trecho "Viviane é corredora. Ela participou da última São Silvestre", há operações inferenciais simples, como ligar um nome ao pronome que o retoma logo adiante no texto (Viviane - ela) com apenas um antecedente possível ou inferir a relação entre corredora e São Silvestre, que requer um conhecimento de que São Silvestre é uma corrida, entre outras inferências elaborativas possíveis, como, por exemplo, de que o sonho de muito corredor é ganhar essa corrida, que ela acontece em São Paulo, entre tantas outras informações que podem ser inferidas a partir dessa expressão de apenas duas frases. Devemos nos lembrar também que à exceção de D1 (localizar informações explícitas em um texto), todos os outros descritores são ou podem ser operarações inferenciais.

Não é nosso objetivo discutir cada descritor isoladamente, mas salientar a complexidade e a diversidade de possibilidades (e, consequentemente, de operações linguístico-cognitivas) que cada um deles encerra. Essa complexidade não é explicidada na matriz, mas pode ser revelada na leitura de textos, tanto no papel quanto nas telas.

\section{Ler é misturar tudo, de um jeito coordenado}

A discussão sobre o que é hipertexto já teve seu apogeu. Atualmente, é bastante consensual que a não-linearidade seja um atributo do hipertexto, seja ele de papel ou de bits. Ribeiro (2008), com Coscarelli (2005b), assumiu a leitura como um processo hipertextual por excelência. De acordo com o modelo de processamento de leitura proposto por Coscarelli (1999), ler é executar diversas operações, que vão desde o reconhecimento da letra até a construção de sentidos mais globais, fazendo inferências e colhendo pistas, de uma maneira coordenada. Ler é movimentar um hipertexto (mental ou modelado). E isso ocorre para a leitura de objetos impressos ou digitais, principalmente porque modelos de leitura, assim como matrizes de habilidades, não costumam considerar o contato com o objeto de ler (do livro ao computador, passando por jornais e outdoors) como algo que faz parte desse hipertexto. 
Por exemplo, considerando-se que o jornal seja uma mídia com características “mosáaiquicas" (SANTAELLA, 2004a), ou seja, produzida de forma descontínua e interconectada, dando ao leitor a possibilidade de selecionar entre textos que lhe interessam, parece importante considerar que as habilidades implicadas no reconhecimento, na manipulação e na seleção de textos nesse objeto sejam fundamentais para a leitura. A ação de cumprir um trajeto proposto pelo jornal é preliminar à leitura e não se deveria ignorar que o texto a ser lido esteja emoldurado por esse ambiente. O tipo de suporte pode, inclusive, ter exercido certas coerções sobre a forma final do texto, como tamanho, tipo e quantidade de parágrafos, etc. O leitor pode ter ou não domínio das indicações projetadas no suporte/texto.

No caso da web, os textos ali expostos encontram outros tipos de coerções. Muito embora a existência do link digital seja um fator elementar nas páginas eletrônicas, Alzamora (2004) afirma que sites de jornais impressos, por exemplo, "primam por apresentarem tímidas propostas hipermidiáticas", no entanto, ainda assim, "a Internet propicia experiências de interação social e de circulação de informações jornalísticas razoavelmente distintas das experiências comunicativas assentadas no paradigma massivo" (ALZAMORA, 2004, p. 107). A despeito de os textos dos jornais serem basicamente os mesmos no papel e na tela, as práticas do leitor sofrem alguma mudança, indo do folhear ao clique, da "olhadinha" ao scroll, da procura manual ao link. Parece-nos necessário tratar as habilidades de leitura desde muito antes da leitura propriamente do texto. Por isso, os descritores do Saeb devem ser entendidos como uma parte do ato de ler não mais importante do que a abordagem inicial do material a ser lido (o contato com o objeto de ler). Nesse sentido, a familiaridade provocada pela simulação do impresso, empregada para dar sensação de reconhecimento de um ambiente velho em um novo (a remidiação, de BOLTER; GRUSIN, 2000), pode se justificar.

\section{Matrizes são abertas}

Se a matriz de leitura do Saeb verifica habilidades mais intimamente ligadas à leitura como atividade um tanto desambientada (no sentido da inscrição no suporte e das práticas que envolvem a leitura), a matriz de lei- 
tura proposta por Dias e Novais (2009) busca focalizar habilidades que vão desde o contato com o suporte até o processamento leitor. Os autores dividem sua matriz em grupos que chamam de Contato, Compreensão e Análise, que seriam mais ou menos o que o Saeb chama de Tópicos. O reconhecimento da área de trabalho do computador, por exemplo, está no grupo Contato, enquanto o contraste entre interfaces de programas está no grupo Análise. Outras matrizes de letramento digital existem e inspiraram o empreendimento desses autores. Das que conhecemos, pode-se citar a lista francesa de habilidades em informática e internet e o elenco que compõe o documento "Technology Standards for Language Learners".

A proposta de Dias e Novais (2009) é relevante e contribui para uma tentativa de explicitação do grupo de habilidades que seja efetivamente importante para que se possa considerar alguém letrado digital. É comum que os trabalhos relacionados a esse tipo de letramento abordem o tema sem explicitar o tipo ou a quantidade de habilidades necessárias para que se forme o "hiperleitor". Dias e Novais (2009) empreendem o trabalho de distinguir, na complexa paisagem dos objetos de ler, as ações fundamentais envolvidas na interação leitor/texto digital, especialmente em telas de computador, cuja interface tornou-se uma espécie de padrão estético-cognitivo para os usuários de máquinas e internet.

Assim como a matriz do Saeb, a matriz de letramento digital (que apelidaremos aqui de "Matrix") é aberta, ou seja, a cada tecnologia surgida que diga respeito à cultura escrita é preciso ampliar, inaugurar ou completar células. Matrizes não deveriam ser representadas como quadros fechados, em uma alusão visual à sua possibilidade de crescimento e complexificação. Conforme houver mudanças no computador (tamanhos, velocidades, interfaces), haverá reconfigurações dos usos e das formas de ler. Conforme as pessoas se apropriam de outros objetos de tecnologia digital (aparelhos de telefonia móvel, minicomputadores, etc.), passam a desenvolver habilidades novas.

Porém, se uma matriz é aberta e incompleta, para que ela serve? Para oferecer parâmetros de desenvolvimento do leitor, especialmente parâmetros que possam guiar as agências de letramento (incluindo-se a escola) e para oferecer guias de avaliação. À construção de uma matriz subjaz uma premissa: há caminhos equivocados. Para se empregar uma matriz na construção de um instrumento de avaliação é preciso considerar que haja, por exemplo, resposta errada, leitura errada e prática errada. 
Possenti (1999) não apenas admite, mas sustenta o que chama de "leitura errada", quando o leitor "pode ter manobrado mal" ao ler um texto. Para o autor, é válido explicar por que um leitor leu como leu, mas é necessário considerar que existam leituras mais alinhadas do que outras. Coscarelli (1999) também considera possível estabelecer parâmetros para leituras mais autorizadas de textos. Leitores mais letrados lançam mão, em grande medida, do que sabem sobre textos e suportes para aceitar e executar essas propostas. Outras vezes, quando não são letrados o suficiente, traçam seus trajetos de maneira desviante, imprevista ou improvisada. A matriz oferece um enquadre desses processamentos, de forma a auxiliar a avaliação das ações de um leitor.

É preciso também reforçar a diferença entre matriz de avaliação e matriz de ensino. Uma matriz de avaliação sofre limites do estilo da avaliação. Numa prova de múltipla escolha nem sempre é possível verificar habilidades que são facilmente testadas em questões abertas. Nem sempre é viável lidar com questões abertas em avaliações em grande escala, pelas dificuldades e demora na correção. Há que se considerar também o tempo da prova. Quanto maior o número de descritores a serem verificados, maior a dificuldade de preparação das provas e maiores devem ser as provas ou o número de cadernos de provas, o que pode acarretar problemas para o tratamento estatístico. Ou seja, há várias razões para que matrizes de avaliação sejam como são (isso não significa que não possam e não devam mudar). No entanto, essas limitações não se aplicam a matrizes de ensino, que devem ser propostas como metas a serem alcançadas por alunos e professores nas práticas pedagógicas das escolas. Essa matriz deve ser mais completa e envolver não apenas habilidades de leitura, mas também de escrita, fala e escuta de textos de diversos gêneros, incluindo nelas habilidades relativas ao exercício dessas competências em ambientes digitais e considerando a produção e a recepção de textos como atividades que acontecem em uma situação comunicativa determinada, em um suporte, em um contexto. Assim, será necessário lidar com questões relativas ao estilo do texto, ao design, ao paratexto, que muitas vezes passavam despercebidas aos linguistas e professores que trabalhavam o texto fora de seu contexto de produção e circulação. A "matrix" de letramento digital pode ser uma das fases de uma matriz de leitura mais completa, assim como a matriz do Saeb nos parece um dos elementos a se verificar na paisagem complexa do ato de ler. 


\section{Considerações para 0 diálogo}

Sabendo que as matrizes de avaliação são, muitas vezes, tomadas como metas para o ensino, chamamos a atenção para a diferença entre esses dois tipos de matriz, que servem a propósitos muito diferentes.

Conscientes das limitações de uma matriz de avaliação, acreditamos que as matrizes de avaliação de leitura precisam ser revistas, a fim de que possam incorporar não apenas os valores ligados à cultura escrita impressa, mas também elementos relativos à multimodalidade e às habilidades relativas à leitura em ambientes digitais.

No caso de serem usadas como matrizes de ensino, elas precisam especificar melhor seus descritores, fazendo juz à complexidade de cada um deles. Isso seria feito fatorando-se os descritores, de modo a explicitar os diversos elementos envolvidos neles e os possíveis efeitos de sentido que podem provocar. Dessa forma, a habilidade descrita por cada descritor ficaria claramente apresentada.

A proposta de Dias e Novais (2009) é o ensaio de uma matriz de letramento digital que, a exemplo de muitos ambientes da Web, deve ser construída de maneira colaborativa e recursiva. A abertura de qualquer matriz deve ser, enfim, um convite à inserção de novos letramentos para serem avaliados ou para servirem como parâmetros para o ensino. 


\section{Agradecimento}

À leitura atenta e positiva de Else Martins.

\section{Referências}

ANDERSON, R. C.; PICHERT, J. W. Recall of previously unrecallable information following a shift in perspective. Journal of Verbal Learning and Verbal Behavior, 17, p. 1-12. 1978. ARAÚJO, Maria Aparecida. Compreensão de hipertexto: sob a perspectiva da teoria da mesclagem. Dissertação (Mestrado em Estudos Linguísticos). Belo Horizonte, Faculdade de Letras, UFMG, 2006.

BEAUGRANDE, R.-A. de; DRESSLER, W. U. Introduction to Text Linguistics. London: Longman, 1981.

BOLTER, Jay D; GRUSIN, Richard. Remediation. Understanding new media. USA: MIT Press, 2000.

BRANSFORD, J.D.; JOHNSON, M.K. Considerations of some problems of comprehension. In. W.G. Chase (Ed.), Visual information processing New York: Academic Press. 1973. p. 383-438. BRASIL. O que é ENADE? Disponível em: <http://www.inep.gov.br/superior/ enade/enade_oquee.htm>. Acesso em 5 de janeiro de 2010.

CARPENTER, P. A. JUST, M. A. Integrative processes in comprehension. In: LABERGE, D. SAMUELS, S. J. (Eds.). Basic processes in reading: perception and comprehension. Hillsdale, NJ: Erlbaum, 1977.

CLARK, H. H. Bridging. In: JOHNSON-LAIRD, P.N., WASON, P.C. (Eds.). Thinking: readings in cognitive science. Cambridge: Cambridge University, 1977. p. 411-20.

COSCARELLI, Carla Viana. Leitura em ambiente multimídia e produção de inferências. 1999. Tese (Doutorado em Estudos Linguísticos). Faculdade de Letras, UFMG, Belo Horizonte, 1999.

COSCARELLI, Carla. Relatório de Pesquisa: A leitura de hipertextos. San Diego, UCSD /Belo Horizonte, FALE/UFMG, 2005a. (mimeo)

COSCARELLI, C. V. Poussin em muitas telas. TXT: leituras transdisciplinares de telas e textos. Ano I, n. 2., dez. 2005.

COSTA VAL, M. Graça. Redação e textualidade. São Paulo: Martins Fontes, 1991

COSTA VAL, Maria da Graça. Repensando a textualidade. In: AZEVEDO, José Carlos (Org.). Lingua Portuguesa em Debate: conhecimento e ensino. Petrópolis: Vozes, 2001. p. 34-51. DIAS, Marcelo Cafiero; NOVAIS, Ana Elisa. Por uma matriz de letramento digital. In: Anais do III Encontro Nacional sobre hipertexto. Belo Horizonte, CEFET-MG, 29, 30, 31 de outubro de 2009. Disponível em < http:/ /www.hipertexto2009.com.br/anais/p-w/poruma-matriz.pdf $>$. Acessado em 7/2/2010.

DUARTE, Viviane Martins. Textos multimodais e letramento: habilidades na leitura de gráficos da Folha de São Paulo por um grupo de alunos do Ensino Médio. Dissertação (Mestrado em Estudos Linguísticos), Belo Horizonte, Faculdade de Letras, UFMG, 2008.

GARNHAM, A. Inference in language understanding: what, when, why and how. In: DEITRICH, R, GRAUMANN C. F. (Eds.). Language processing in social context. NorthHoland: Elsevier Science Publishers, 1989.

HALLIDAY, M.A.K.; HASAN, Ruqaiya. Cohesion in English. London: Longman, 1976. HUBBARD, Philip; KESSLER, Greg. Help Shape TESOL's New Technology Standards. Proceedings of WorldCALL, Japão, ago. 2008. Disponível em 
<http://www.j-let.org/ wcf/proceedings/d-025.pdf>. Acessado em 11 de jan. 2010. KEENAN, J. M., POTTS, G. R., GOLDING, J. M., JENNINGS, T. M. Which elaborative inferences are drawn during reading? a question of methodologies. In: BALOTA, D. A., FLORES D'ARCAIS, G. B., RAYNER. K. Comprehension processes in reading. Hillsdale, New Jersey: Lawrence Erlbaum Associates, 1990. p. 377-341.

KINTSCH, W.; VAN DIJK, T.A. Toward a model of text comprehension and production. Psychological Review, v. 85, n. 5, p. 363-394, 1978.

NOVAIS, Ana Elisa Costa. Leitura nas interfaces gráficas de computador. compreendendo a gramática das interfaces. Dissertação (Mestrado em Estudos Linguísticos). Belo Horizonte, UFMG, 2008. PAIVA, Francis Artuso. A leitura de infográficos da revista Superinteressante: procedimentos de leitura e compreensão. Dissertação (Mestrado em Estudos Linguísticos), Belo Horizonte, Faculdade de Letras, UFMG, 2009.

RIBEIRO, Ana Elisa F. Navegar lendo, ler navegando - Aspectos do letramento digital e da leitura de jornais. 2008. 248 f. Tese. (Doutorado em Estudos Linguísticos, Linguagem e Tecnologia). Belo Horizonte, Faculdade de Letras, UFMG, 2008.

RIBEIRO, Ana Elisa. O layout e a leitura: implicações da diagramação do jornal na compreensão leitora. In: 180 Encontro Anual da Compós, 2009, Belo Horizonte. Anais Compós 2009. Belo Horizonte : PUC Minas, 2009.

SANTAELLA, Lucia. Antecedentes da Alinearidade hipermidiática nas mídias mosaiquicas. In: BRASIL, André et al. (Orgs.) Cultura em fluxo: novas mediações em rede. Belo Horizonte: Editora PUC Minas, 2004.

SCOTT, Michael. Lendo nas entrelinhas. Ilha do Desterro. Florianópolis, n.13, p. 101-123, 1985. SEIFERT, Colleen M. Content-based inferences in text. In: GRAESSER, A. C., BOWER, G. H. Inferences and text comprehension. San Diego: Academic Press. 1990. p. 103-122. THORNDYKE, Perry. Cognitive structures in comprehension and memory of narrative discourse. Cognitive Psychology, v. 9, p. 77-110, 1977.

VAN DEN BROEK, Paul. The causal inference maker: towards a process model of inference generation in text comprehesion. In: BALOTA, D. A.; FLORES D'ARCAIS, G. B.; RAYNER. K. Comprehension processes in reading. Hillsdale, New Jersey: Lawrence Erlbaum Associates, 1990. p. 423-445.

\section{Nota}

1 Respectivamente disponíveis em: <http://www2.c2i.education.fr/sections/en/c2il1/c2i1ref> e $<$ http://www.tesol.org/s_tesol/sec_document.asp?CID=1972\&DID=12051>. Para uma discussão sobre a matriz do TESOL, ver Hubbard e Kessler (2008).

Recebido: $11 / 03 / 2010$

Aprovado: 09/08/2010

Contato:

Centro Federal de Educação Tecnológica de Minas Gerais

Av. Amazonas, 5253 - Nova Suiça

Belo Horizonte - MG

CEP $30480-000$ 